\title{
Investigation of the relationship between depth of overhang and amount of daylight indicators in office buildings of Kerman city
}

\author{
Ali Yazhari Kermani ${ }^{1}$, Farshad Nasrollahi ${ }^{1^{*}}$, Mohammadjavad Mahdavinejad $^{2}$ \\ ${ }^{1}$ Department of Architecture, School of Architecture and Urbanism, Art University of Isfahan, Isfahan, Iran \\ ${ }^{2}$ Department of Architecture, School of Architecture and Urbanism, Tarbiat Modares University, Tehran, Iran
}

\begin{abstract}
Background: The use of daylight in offices has become an effective strategy to improve the quality of indoor space and energy efficiency. There is enough potential to have daylight autonomy in Kerman as a city with more than 300 sunny days a year. Therefore, this study aimed to investigate the relationship between facades configuration and the amount of daylight in office buildings of Kerman.

Methods: This study was carried out based on the simulation in DesignBuilder software (DBS). In this study, 36 typical rooms, with the same physical characteristics $(4 \mathrm{~m} \times 6 \mathrm{~m} \times 4 \mathrm{~m})$, with window-to-wall ratio (WWR) between 10-90\% with four overhang depths $(0,0.5,1$ and $1.5 \mathrm{~m})$ were modeled.

Results: Based on daylight utilization, the results indicate that an optimal WWR for a room with 1 $\mathrm{m}$ overhang depth ranged from $50 \%$ to $70 \%$. Also, the room with $0.5 \mathrm{~m}$ overhang depth and without overhang, had suitable daylight while WWR was at least $50 \%$, but the room with $1.5 \mathrm{~m}$ depth would not encounter glare problem even when WWR was $90 \%$.

Conclusion: The results confirm that overhang depth and WWR have significant effect on daylight parameters such as daylight factor (DF), work plane illuminance (WPI), and WPI ratio. Hence, these insights can be useful for designers to design buildings with lower energy use and higher daylight quality, when enough light is provided in office rooms.

Keywords: Sunlight, Office, Kerman, Uniformity, Design software

Citation: Yazhari Kermani A, Nasrollahi F, Mahdavinejad M. Investigation of the relationship between depth of overhang and amount of daylight indicators in office buildings of Kerman city. Environmental Health Engineering and Management Journal 2018; 5(3): 129-136. doi: 10.15171/EHEM.2018.18.
\end{abstract}

\section{Article History:}

Received: 9 January 2018

Accepted: 14 July 2018

ePublished: 10 September 2018

\author{
*Correspondence to: \\ Farshad Nasrollahi \\ Email: f.nasrollahi@aui.ac.ir
}

\section{Introduction}

In the primary steps of design process, prediction of building performance has an effective influence on the future performance of buildings and their energy consumption (1-4). It is essential to use these insights in the early design stages to improve the efficiency of buildings. However, in practice, designers use simulation tools in the later stages of design $(5,6)$. In performance modeling, architects try to inform decisions about building envelope, façade configuration, shading device and environmental factors (7). In the face of projects, architects often try to apply device facades with large transition surface area to use free daylight provided by the sun.

Daylight is a useful and acceptable parameter for providing energy efficiency and visual comfort in a friendly building. However, it is an important factor to create delightful visible environment in modern architecture. Daylight makes indoor environment to be more attractive and pleasant for people who prefer to have a healthier livable working space $(8,9)$.

According to sustainability challenges such as renewable energy sources and environmental quality, natural light is a great resource to improve energy consumption by minimizing the lighting, heating and cooling load $(10,11)$ (Figure 1).

More than $30 \%$ of lighting energy can be saved by two main solutions: increasing the naturally available indoor daylight and the use of efficient artificial lighting devices (12).

Window size, as one of the most effective factors, which is labeled as the window-to-wall ratio (WWR), influences the daylight quality and thermal performance (13-15).

In 1984, daylighting was studied in relation to windows without any movable shading devices in Washington DC with variable WWR (10\%, 20\% and 50\%) and several orientations using daylight program (DALITE) (16). In a parametric study in the United Kingdom and Brazil, the results of scale and simulation models showed 


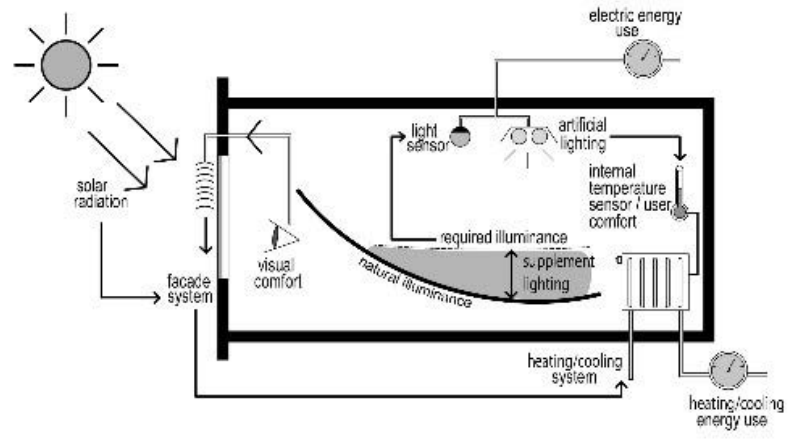

Figure 1. Influence of daylight on heating, cooling and artificial lighting systems.

the importance of window sizes and room features in improving electric lighting consumption and providing maximal view (17). A study in Sweden showed that daylight autonomy for $100 \%$ WWR with louvers was $50 \%$ and for the case of $60 \%$ WWR with louver systems, it decreased to $45 \%(18)$. In a city in saturation region such as Montréal, 30\% WWR provides suitable daylight in office buildings (19). Energy simulation of an office in the tropical area has shown that $100 \%$ WWR can increase energy consumption by $15 \%$ more than $30 \%$ WWR in a building (20).

A simulation research based on daylight for different orientations indicated that an optimal WWR ranging from $20 \%$ for south orientation to $40 \%$ for north orientation was acceptable (21). In another research in Japan, as the WWR decreased, the $\mathrm{CO}_{2}$ emissions also decreased and in 30\%-50\% WWR, the $\mathrm{CO}_{2}$ emissions were minimized and with increasing the WWR, the $\mathrm{CO}_{2}$ decreased (2).

Several studies have examined shading device as a daylight control device besides WWR. They investigated the relationship among critical variables such as energy consumption, air pollution and natural sources (22). The ratio between the amount of daylight in two conditions, with and without shading device, was used to evaluate the daylight efficiency of shading device. If the overhang depth is equal to the height of window, the amount of daylight will reduce by $60 \%$, without considering the reflection and entering the light from sides (23). The amount of daylight factor (DF) can be minimized by $50 \%$ if the depth of shading device be appropriate. Furthermore, the amount of DF is between $2 \%$ and $6 \%$ in different positions with respect to the window under clear sky condition (24). There is a relationship between shading device, daylighting and energy consumption. Shading devices also influence the amount of luminance, since they can provide luminance more than $500 \mathrm{~cd} / \mathrm{m}^{2}$. Shading device with dark color cannot provide acceptable work plane illuminance (WPI), even when the sky is clear and global illuminance is around 65000 to 95000 lux. The effect of different overhang ratios and light shelf configurations on the amount of daylight and uniformity of daylight in the room was investigated. The results demonstrated that the amount of daylight at the rear of the room decreased by increasing the depth of shading device (25).

The daylight performance is assessed for hot and arid climates using specific shading devices. The effect of shading device depends on the surface reflectance. It has been revealed that $70 \%$ to $80 \%$ reduction in the illuminance level occurs when surface reflectance reduces by $50 \%$ (26). The average DF reduces $50 \%$ by using shading devices. Besides using shading devices, the problems of glare and contrast had been minimized (24). Ho et al showed that an appropriate use of solar shading not only improves the illuminance level, but also reduces energy consumption of lighting by 71.5 urned on (27). Scale model was used to investigate the effect of shading device and window area on DF in sub-tropical climate $(28,29)$. In addition, the impacts of external shading devices on the incident solar radiation and daylighting were investigated in office rooms under specific sky conditions (30). The best orientation for horizontal and vertical shading devices that provides acceptable illuminance was estimated when solar heat gain was in the minimum position (31).

Briefly, previous research consistently shows that increasing WWR is not always necessary to provide enough available daylighting and reduce electric lighting. The main objective of this parametric study was to determine the optimal WWR and overhang size, under different daylight indicators as a shading device in office buildings of Kerman located in a hot and dry arid climate, to improve the indoor daylight quality.

\section{Methods}

This paper proposed an analysis with scale model. This technique is called 'reference office' as a lighting assessment methodology (13,32-35).

\section{Reference office description}

The reference office model is used for comparative analysis of different studies on natural and artificial lighting to represent the characteristics of a simple typical office room. This method is commonly used for a standard concept design in any location. As a research method, "Shoebox" model has been used as a default type of office room to assess daylight availability and lighting technology. Since its introduction in 1997, more than forty papers have used "Shoebox" as a sample, by deploying various dimensions between 3 and $5 \mathrm{~m}$ width, 5 and $8 \mathrm{~m}$ length and 3 and 4 $\mathrm{m}$ height.

Using "Shoebox" model allows us to conduct a comparative study on different results and also continue to develop achievement in actual model. Having access to a set of valid simulation and performing a comparative analysis with the same cases under various conditions, are the merits of the reference model methodology (32).

Lighting and energy simulation program

Computer simulations are suitable to improve building 
optimization as well as indoor climate quality and energy efficiency. Evaluating both thermal and daylight evaluations by computer simulations is a reasonable idea for the prediction of physical features such as façade and window design strategies. This study was conducted by applying the validated dynamic daylight simulation software (DesignBuilder, DBS), which is a radiance-based one (36).

DBS version 1.8.1 (36) software evaluates the influence of configuration and physical characteristics of a building on energy efficiency and daylighting in several zones (37). This program is a dynamic daylighting and energy simulation software, which can demonstrate daylight performance in virtual space samples. DBS uses EnergyPlus as its simulation engine, which calculates the heating, cooling and lighting load of buildings according to ASHRAE standard method (38). First, the main question that comes to mind about the usage of any simulation software is related to its validation and calculation accuracy, in relation to the actual demands. Previous studies have shown that this software calculates the demands of energy and lighting with a high definitude (39). The difference between the amount of heating and cooling loads by EnergyPlus simulation with an experimental measurement during 24 hours was very significant (3\%5\%) (40). in another research, this validation was about $13 \%$ in terms of energy and lighting consumption (41). In Iran, the results of a calibration study by DBS and Ecotect software based on an experimental test showed a difference of $23 \%$ in energy consumption and $14 \%$ in daylight estimation (42).

The present study adopted the indoor daylight quality of several glazed window types in four types of office room in Kerman using DBS.

The simulation models were carried out by lighting analysis and the date and location were set. Daylight indicators including DF, WPI, WPI Ratio, were calculated. Different analyses indicated the effect of shading devices and window size on daylight quality in office rooms. Microsoft (MS) Excel was used for drawing tables and charts and descriptive comparison analyses. Excel charts showed the behavior of light with window size and overhang depth in an office.

\section{Measurement indicators}

The metrics used for daylighting analysis, were DF, WPI and WPI Ratio. These metrics were proposed by the Illuminating Engineering Society (IESNA) and International Commission of Illuminance (CIE) to assess the sufficiency of daylighting quality in an interior working environment (14,25,43-45).

Maximum and minimum set points of daylight indicators were defined according to several standards, which propose the indoor conditions of buildings based on visual comfort and user satisfaction. DF, WPI and WPI Ratio are the output parameters of lighting computations in DBS.

The basic model in this research represented a southfacing side office room, located in Kerman city (30.2839 $\mathrm{N}, 57.0834^{\circ} \mathrm{E}$ ), with a hot and dry climate. The room was not adjoined with other rooms. The dimensions of the space were $6 \mathrm{~m}$ width, $4 \mathrm{~m}$ length and $4 \mathrm{~m}$ height, which represents the common height of the majority of office rooms in Kerman. The reflectance amounts of the ceiling, walls, floor and window were assumed to be 70, 30, 90 and 80 as the reflectance of general materials in an actual model (Table 1). The window sizes were in a variable range between $10 \%$ and $90 \%$ WWR with four types of overhangs $(0,0.5,1,1.5 \mathrm{~m})$.

In total, four office rooms with $6 \mathrm{~m}$ length, $4 \mathrm{~m}$ width and $4 \mathrm{~m}$ overhang height were modeled. One of the rooms has no overhang. An overhang with $0.5 \mathrm{~m}$ depth was modeled in one of the rooms. In another one, the depth of overhang was considered $1 \mathrm{~m}$. Finally, the last model had an overhang with $1.5 \mathrm{~m}$ depth. Furthermore, different sizes of south-facing window, from $10 \%$ to $90 \%$ (WWR), were modeled in all four models. Therefore, 36 different models with different window areas and different overhang depths were simulated in DBS software (Figure 2).

In the construction section of DBS program, materials and different layers of external walls and roofs were specified. In the opening section of DBS, window materials and layers were specified: windows had 2 layers with $6 \mathrm{~mm}$ thickness and $13 \mathrm{~mm}$ argon gas between the layers. Finally, in daylighting section, all 30 models were analyzed and different indicators of daylight such as DF, average WPI and uniformity ratio were recorded for each model.

\section{Results}

The results obtained from 36 models were calculated and analyzed by MS Excel program. Data were classified into three categories in terms of daylight performance indicators (DF, WPI and WPI Ratio).

Table 1. The parameters of a typical office used for computer simulation

\begin{tabular}{ll}
\hline Office Parameter & Average Reflectance (\%) \\
\hline Walls & 70 \\
Floor & 30 \\
Ceiling & 90 \\
Window & 80 \\
\hline
\end{tabular}

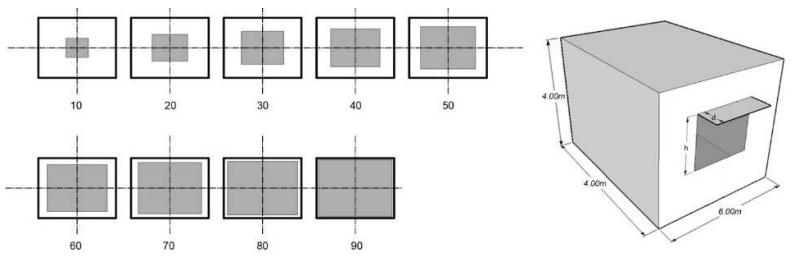

Figure 2. Window size variations of office rooms with different overhang depths. 
Evaluation of office rooms with different WWRs and overhang depths in terms of DF

The amount of DF [(internal/external illuminance $) \times 100]$ and different depths of overhang and WWRs of an office room model were simulated, assuming that the models were south-facing. The data are presented in Table 2.

As shown in Table 2, for different overhang depths and WWRs, the maximum amount of DF was 7.71 for $90 \%$ WWR, when the room was without overhang and was under overcast sky condition. However, almost for all positions of overhang depth in the case of $10 \%$ WWR, the minimum amount of DF was obtained. The DF monotonically increases by increasing WWR in all depths of overhang. According to the Dubois recommendation, DF should be between $2 \%$ and $5 \%$ (45). It means that the acceptable range of DF is between $50 \%$ and $60 \%$ WWR, when the model has the best daylight quality. The space between two bold lines in Figure 3 shows the acceptable range of DF for the research model. However, the DF trend shows that in a hot and dry climate, using larger windows over $60 \%$ WWR without overhang becomes a steely glare and to provide the minimum available daylighting with or without overhang, WWR should be at least 50\%.

Evaluation of office rooms with different WWRs and overhang depths in terms of WPI

The amount of WPI in different models with different WWRs and overhang depths are summarized in Table 3. The acceptable rate for WPI was set according to Dubois standard. Although WPI more than 300 lux for both paper work and computer work was ideal, but it did not enhance more than 500 lux (45). Furthermore, it was revealed that an office room without overhang could not achieve the

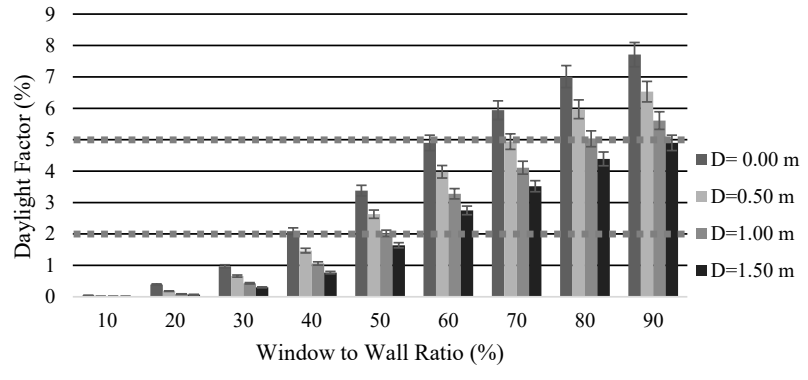

Figure 3. Amount of daylight factor in different models with different WWR according to the depth of overhang

ideal condition in terms of WPI at all (Table 3). Because the room without overhang and with $30 \%$ WWR had a WPI less than 300 lux but in cases with $40 \%$ WWR, WPI was more than 500 lux. If the office room had overhang with $0.5 \mathrm{~m}$ depth, the ideal condition of daylight would be provided when $40 \%$ WWR was applied. In addition, when overhang depth was considered $1 \mathrm{~m}$, the office room with $50 \%$ WWR could provide 505 lux WPI and the amount of WPI in an office room with an overhang with $1.5 \mathrm{~m}$ depth was 384 lux.

Finally, the least useful daylight illuminance, without artificial lighting, was observed at $40 \%$ WWR, when the maximum overhang depth was $0.5 \mathrm{~m}$. Against that, designing windows over than $50 \%$ WWR is not suitable for all conditions.

Evaluation of office rooms with different WWRs and depths of overhang in terms of uniformity ratio The input parameters used in this study for WPI Ratio analysis are summarized in Table 4, which shows the

Table 2. Amount of daylight factor in different models with different WWRs according to the depth of overhang

\begin{tabular}{|c|c|c|c|c|c|c|c|c|c|}
\hline \multirow{2}{*}{ Overhang Depth } & \multicolumn{9}{|c|}{ WWR } \\
\hline & $10 \%$ & $20 \%$ & $30 \%$ & $40 \%$ & $50 \%$ & $60 \%$ & $70 \%$ & $80 \%$ & $90 \%$ \\
\hline $\mathrm{D}=0.0 \mathrm{~m}$ & 0.04 & 0.39 & 0.97 & 2.09 & 3.38 & 4.90 & 5.94 & 7.01 & 7.71 \\
\hline $\mathrm{D}=0.5 \mathrm{~m}$ & 0.01 & 0.18 & 0.66 & 1.47 & 2.63 & 3.98 & 4.94 & 5.97 & 6.53 \\
\hline $\mathrm{D}=1.0 \mathrm{~m}$ & 0.01 & 0.09 & 0.43 & 1.06 & 2.02 & 3.28 & 4.11 & 5.03 & 5.61 \\
\hline $\mathrm{D}=1.5 \mathrm{~m}$ & 0.01 & 0.07 & 0.30 & 0.77 & 1.64 & 2.75 & 3.52 & 4.39 & 4.90 \\
\hline
\end{tabular}

Table 3. Amount of work plane illuminance in different models with different WWRs according to the depth of overhang

\begin{tabular}{|c|c|c|c|c|c|c|c|c|c|}
\hline \multirow{2}{*}{ Overhang Depth } & \multicolumn{9}{|c|}{ WWR } \\
\hline & $10 \%$ & $20 \%$ & $30 \%$ & $40 \%$ & $50 \%$ & $60 \%$ & $70 \%$ & $80 \%$ & $90 \%$ \\
\hline$D=0.0 \mathrm{~m}$ & 14.9 & 105.7 & 273.4 & 555.3 & 841.8 & 1228.6 & 1270.4 & 1310.2 & 1332.5 \\
\hline $\mathrm{D}=0.5 \mathrm{~m}$ & 2.03 & 37.2 & 166.6 & 398.8 & 649.3 & 1045.3 & 1144.4 & 1186.6 & 1201.8 \\
\hline $\mathrm{D}=1.0 \mathrm{~m}$ & 1.9 & 13.0 & 88.6 & 250.5 & 505.4 & 876.7 & 962.9 & 1028.0 & 1061.0 \\
\hline $\mathrm{D}=1.5 \mathrm{~m}$ & 1.7 & 10.8 & 50.63 & 163.1 & 384.0 & 744.3 & 820.5 & 901.3 & 932.6 \\
\hline
\end{tabular}


Table 4. Amount of uniformity ratio in different models with different WWRs according to the depth of overhang

\begin{tabular}{|c|c|c|c|c|c|c|c|c|c|}
\hline \multirow{2}{*}{ Overhang Depth } & \multicolumn{9}{|c|}{ WWR } \\
\hline & $10 \%$ & $20 \%$ & $30 \%$ & $40 \%$ & $50 \%$ & $60 \%$ & $70 \%$ & $80 \%$ & $90 \%$ \\
\hline $\mathrm{D}=0.0 \mathrm{~m}$ & 0.00 & 0.08 & 0.12 & 0.28 & 0.44 & 0.64 & 0.64 & 0.72 & 0.76 \\
\hline $\mathrm{D}=0.5 \mathrm{~m}$ & 0.04 & 0.16 & 0.16 & 0.28 & 0.48 & 0.68 & 0.72 & 0.76 & 0.76 \\
\hline $\mathrm{D}=1.0 \mathrm{~m}$ & 0.08 & 0.20 & 0.24 & 0.32 & 0.56 & 0.72 & 0.76 & 0.80 & 0.80 \\
\hline $\mathrm{D}=1.5 \mathrm{~m}$ & 0.12 & 0.32 & 0.32 & 0.40 & 0.60 & 0.76 & 0.84 & 0.84 & 0.88 \\
\hline
\end{tabular}

effect of overhang depth on the amount of WPI Ratio and uniformity ratio when various WWRs (10\%-90\%) were applied. WPI uniformity is important to keep away places from contrast and better lighting quality. The acceptable illuminance uniformity (minimum/average) over any task area should be lower than 0.8 CIE (1986) and CIBSE (1994) (44,46). Many lighting standards require a uniformity ratio of 0.8 (minimum/average) or 0.7 (minimum/maximum). However, some research indicated that a ratio of 0.5 (minimum/maximum) may be even acceptable (45).

Table 4 shows that for a window with WWR more than $60 \%$, uniformity was around $0.7-0.8$, which is acceptable for excellent daylight uniformity, according to daylight standards. Moreover, Table 3 shows that WPI Ratio or uniformity ratio below 0.5 was obtained for $50 \%$ WWR or less. WPI Ratios show the urgency to use solar shading devices for $50 \%, 60 \%$ and $70 \%$ WWR. If the office room had no overhang depth, the ideal daylight uniformity would be provided when $80 \%-90 \%$ WWR was applied. In addition, when overhang depth was considered between $0.5 \mathrm{~m}$ and $1.5 \mathrm{~m}$, the office room with a WWR more than $50 \%$ could provide acceptable uniformity. The optimal WPI Ratios without overhang in this section, also were proposed by $70 \%$ and $80 \%$ glazing type.

\section{Discussion}

In this study, simulation technique by DBS was used to carry out daylight analyses and characterize the façade configuration such as WWR and overhang depth. Optimizing daylight parameter is important as it influences energy consumption through supplementary artificial lighting, heating and cooling demand besides providing the visual comfort (47). The results show that, office rooms with overhang depth of $0.5 \mathrm{~m}$ and $1 \mathrm{~m}$ had enough potential for daylight utilization, when they had at least 50\% WWR. Furthermore, these two office rooms with $80 \%$ and more than $80 \%$ WWR, probably encountered glare problems because they had an average of DF more than 5\%. According to Figure 3, office room with overhang depth of $1.5 \mathrm{~m}$, will not encounter glare problem even though $90 \%$ WWR is applied. The office room without overhang, will have acceptable potential for daylight utilization when WWR is considered $40 \%$,
$50 \%$ or $60 \%$. Based on CIE and CIBSE standards, DF had an acceptable range between 0.2 and 0.5 in rooms with different WWRs and overhang depths $(44,46)$.

As shown in Figure 4, the amount of WPI in different models with different WWRs and depths of overhang, could be increased by increasing WWR. Against, it can be concluded that with increasing the depth of overhang, WPI decreases in all ranges of WWR. Therefore, an ideal condition can be provided with larger window area while a greater depth of overhang is applied. The license predicts that the optimum daylight illuminance is in the range 300 500 lux, which is specified by the space between bold lines in the graph. The results show that for $40 \%$ WWR on a south orientation with no overhang, daylight supported the model with 500 lux, which is equal to a same case in Montreal by $30 \%$ WWR in the cold region (14). As shown in the chart analysis, the maximum acceptable WWR with overhang was $50 \%$ whenever the available daylight was approximately 500 lux. With the same research in Sweden, the results indicated that an office glazed to $100 \%$ does not provide significantly more daylight on the office desk than a $60 \%$ glazed office both with and without shading system (18). Large transparent surface causes glare problem by entering a highly amount of daylight in office spaces (21). Thus, shading devices should be prevented discomfort glare and energy waste besides allowing complain view. According to Figure 5, window to façade ratios between $10 \%-90 \%$ were considered for uniformity ratio analysis. However, with increasing depth of overhang, WPI and uniformity ratios were also increased, but in this case, the amount of uniformity ratio does not reach the acceptable

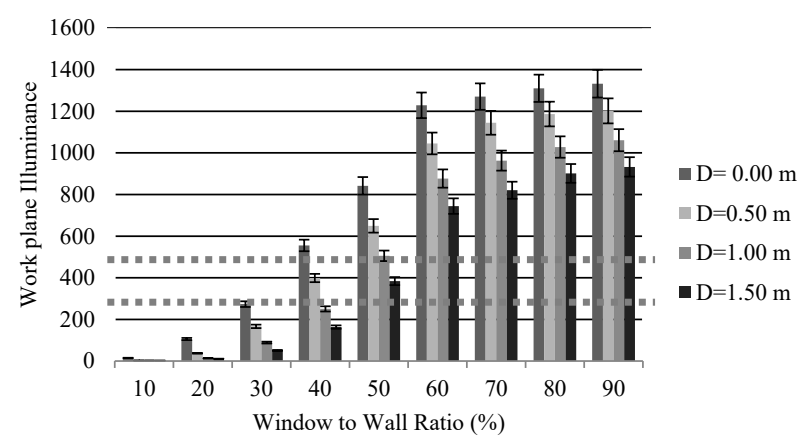

Figure 4. Amount of work plane illuminance in different models with different WWRs according to the depth of overhang 


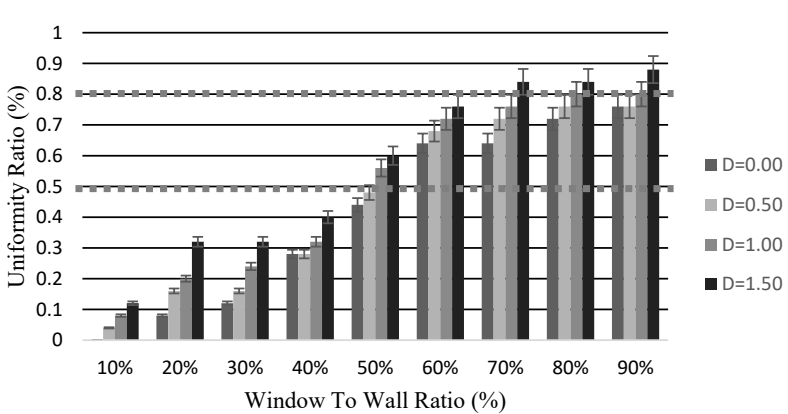

Figure 5. Amount of uniformity ratio in different models with different WWRs according to the depth of overhang.

condition. As the result shown, 50\%-90\% WWR has satisfying goals in the case of uniformity ratio for offices in Kerman with clear sky condition.

\section{Conclusion}

According to the results, increasing depth of overhang as a shading device can influence different daylight indicators such as DF, WPI and WPI Ratio. Depth of overhang has a direct relationship between with uniformity ratio but it has a reverse relationship with WPI and DF. Using overhang has a significant effect on daylight quality and it can provide enough daylight inside rooms when larger window area is applied. So it can influence the design of façade and provide wide view for occupants. Providing enough daylight potential in office room, not only causes more energy saving but also reduces air pollution caused by energy consumption. Furthermore, overhang can enhance the amount of uniformity ratio but it is not sufficient. Thus, shading devices are used more repeatedly in glazed buildings to preserve the same quality of daylight as in a building with a general facade.

The increase of WWR not only could not provide satisfying condition for indoor daylight quality, but also caused glare problem or increased energy consumption. However, findings of this research can be used in energy efficiency and specifically, daylight quality in office buildings of Kerman with a hot and arid climate in Iran. Therefore, enough daylight potential reduces the electricity consumption with lighting devices. Thus, the result of this research can help designer to design office rooms with suitable WWR and overhang depth for providing sufficient daylight without energy consumption.

\section{Acknowledgements}

This study is extracted from the PhD thesis of the first author which conducted at Department of Architecture, Art University of Isfahan. The authors would like to gratitude all people who contributed in this study.

\section{Ethical issues}

The authors certify that all data collected during the study are as stated in the manuscript, and no data from the study has been or will be published separately elsewhere.

\section{Competing interests}

The author declare that he has no competing interests.

\section{Authors' contributions}

All authors participated in the data collection, analysis, and interpretation. All authors critically reviewed, refined, and approved the manuscript.

\section{References}

1. Granadeiro V, Duarte JP, Correia JR, Leal VM. Building envelope shape design in early stages of the design process: Integrating architectural design systems and energy simulation. Automation in Construction 2013; 32: 196-209. doi: 10.1016/j.autcon.2012.12.003.

2. Hiyama K, Glicksman L. Preliminary design method for naturally ventilated buildings using target air change rate and natural ventilation potential maps in the United States. Energy 2015; 89: 655-66. doi: 10.1016/j.energy.2015.06.026.

3. Samuelson H, Claussnitzer S, Goyal A, Chen Y, Romo-Castillo A. Parametric energy simulation in early design: high-rise residential buildings in urban contexts. Build Environ 2016; 101: 19-31. doi: 10.1016/j. buildenv.2016.02.018.

4. Wen L, Hiyama K, Koganei M. A method for creating maps of recommended window-to-wall ratios to assign appropriate default values in design performance modeling: a case study of a typical office building in Japan. Energy Build 2017; 145: 304-17. doi: 10.1016/j.enbuild.2017.04.028.

5. Attia SG, Gratia E, De Herde A, Hensen JL. Simulationbased decision support tool for early stages of zero-energy building design. Energy Build 2012; 49: 2-15. doi: 10.1016/j. enbuild.2012.01.028.

6. The American Institute of Architects. An Architect's Guide to Integrating Energy Modeling in the Design Process. Washington, DC: AIA; 2012.

7. Lin $\mathrm{SH}$, Gerber DJ. Designing-in performance: a framework for evolutionary energy performance feedback in early stage design. Automation in Construction 2014; 38: 59-73. doi: 10.1016/j.autcon.2013.10.007.

8. Li DH, Lam JC. An investigation of daylighting performance and energy saving in a daylit corridor. Energy Build 2003; 35(4): 365-73. doi: 10.1016/S0378-7788(02)00107-X.

9. Alrubaih MS, Zain MF, Alghoul MA, Ibrahim NL, Shameri MA, Elayeb O. Research and development on aspects of daylighting fundamentals. Renewable and Sustainable Energy Reviews 2013; 21: 494-505. doi: 10.1016/j. rser.2012.12.057.

10. Ochoa CE, Aries MB, van Loenen EJ, Hensen JL. Considerations on design optimization criteria for windows providing low energy consumption and high visual comfort. Appl Energy 2012; 95: 238-45. doi: 10.1016/j. apenergy.2012.02.042.

11. Pellegrino A, Cammarano S, Lo Verso VR, Corrado V. Impact of daylighting on total energy use in offices of varying architectural features in Italy: results from a parametric study. Build Environ 2017; 113: 151-62. doi: 10.1016/j.buildenv.2016.09.012. 
12. Li DH, Lam TN, Wong SL. Lighting and energy performance for an office using high frequency dimming controls. Energy Convers Manag 2006; 47(9-10): 1133-45. doi: 10.1016/j.enconman.2005.06.016.

13. Pino A, Bustamante W, Escobar R, Pino FE. Thermal and lighting behavior of office buildings in Santiago of Chile. Energy Build 2012; 47: 441-9. doi: 10.1016/j. enbuild.2011.12.016.

14. Shen H, Tzempelikos A. Sensitivity analysis on daylighting and energy performance of perimeter offices with automated shading. Build Environ 2013; 59: 303-14. doi: 10.1016/j.buildenv.2012.08.028.

15. Grynning S, Gustavsen A, Time B, Jelle BP. Windows in the buildings of tomorrow: Energy losers or energy gainers? Energy Build 2013; 61: 185-92. doi: 10.1016/j. enbuild.2013.02.029.

16. Treado S, Gillette G, Kusuda T. Daylighting with windows, skylights, and clerestories. Energy Build 1984; 6(4): 319-30. doi: 10.1016/0378-7788(84)90015-X.

17. Ghisi E, Tinker JA. An ideal window area concept for energy efficient integration of daylight and artificial light in buildings. Build Environ 2005; 40(1): 51-61. doi: 10.1016/j. buildenv.2004.04.004.

18. Bülow-Hübe H. Daylight in glazed office buildings: a comparative study of daylight availability, luminance and illuminance distribution for an office room with three different glass areas. Lund, Sweden; Division of Energy and Building Design Department of Architecture and Built Environment; 2008.

19. Krarti M, Erickson PM, Hillman TC. A simplified method to estimate energy savings of artificial lighting use from daylighting. Build Environ 2005; 40: 747-54. doi: 10.1016/j. buildenv.2004.08.007.

20. Poirazis H, Blomsterberg A, Wall M. Energy simulations for glazed office buildings in Sweden. Energy Build 2008; 40(7): 1161-70. doi: 10.1016/j.enbuild.2007.10.011.

21. Dubois MC, Flodberg K. Daylight utilisation in perimeter office rooms at high latitudes: Investigation by computer simulation. Light Res Technol 2013; 45(1): 52-75. doi: 10.1177/1477153511428918.

22. Khan MM, Zaman K, Irfan D, Awan U, Ali G, Kyophilavong $\mathrm{P}$, et al. Triangular relationship among energy consumption, air pollution and water resources in Pakistan. J Clean Prod 2016; 112(Pt 2): 1375-85. doi: 10.1016/j.jclepro.2015.01.094.

23. Cheng CL, Liao LM, Chou CP. A study of summarized correlation with shading performance for horizental shading devices in Taiwan. Solar Energy 2013; 90: 1-16. doi. org/10.1016/j.solener.2013.01.007.

24. Fairuz Syed Fadzil S, Sia SJ. Sunlight control and daylight distribution analysis: the KOMTAR case study. Build Environ 2004; 39(6): 713-7. doi: 10.1016/j.buildenv.2003.12.009.

25. Robbins CL. Daylighting: Design and Analysis. New York: Van Nostrand Reinhold; 1985.

26. Al-Shareef FM, Oldham DJ, Carter DJ. A computer model for predicting the daylight performance of complex parallel shading systems. Build Environ 2001; 36(5): 605-18. doi: 10.1016/S0360-1323(00)00084-6.

27. Ho MC, Chiang CM, Chou PC, Chang KF, Lee CY. Optimal sun-shading design for enhanced daylight illumination of subtropical classrooms. Energy Build 2008; 40(10): 1844-
55. doi: 10.1016/j.enbuild.2008.04.012.

28. Chou CP. The performance of daylighting with shading device in architecture design. Tamkang Journal of Science and Engineering 2004; 7(4): 205-12.

29. Cheng CL, Chen CL, Chou CP, Chan CY. A mini-scale modeling approach to natural daylight utilization in building design. Build Environ 2007; 42(1): 372-84. doi: 10.1016/j.buildenv.2005.08.004.

30. Zemmouri N, Schiller ME. Effects of sun controls on buildings interior lighting and thermal environment in hot arid regions. Rev Energ Ren 2004;7(1):45-52.

31. Alzoubi HH, Al-Zoubi AH. Assessment of building façade performance in terms of daylighting and the associated energy consumption in architectural spaces: vertical and horizontal shading devices for southern exposure facades. Energy Convers Manag 2010; 51(8): 1592-9. doi: 10.1016/j. enconman.2009.08.039.

32. Reinhart CF, Mardaljevic J, Rogers Z. Dynamic daylight performance metrics for sustainable building design. Leukos 2006; 3(1): 7-31. doi: 10.1582/LEUKOS.2006.03.01.001.

33. Singh R, Lazarus IJ, Kishore VV. Effect of internal woven roller shade and glazing on the energy and daylighting performances of an office building in the cold climate of Shillong. Appl Energy 2015; 159: 317-33. doi: 10.1016/j. apenergy.2015.09.009.

34. Cai W, Yue J, Dai Q, Hao L, Lin Y, Shi W, et al. The impact of room surface reflectance on corneal illuminance and rule-of-thumb equations for circadian lighting design. Build Environ 2018; 141: 288-97. doi: 10.1016/j. buildenv.2018.05.056.

35. Kosir M, Gostisa T, Kristl Z. Influence of architectural building envelope characteristics on energy performance in Central European climatic conditions. Journal of Building Engineering 2018; 15: 278-88. doi: 10.1016/j. jobe.2017.11.023.

36. Design Builder Software Ltd. DesignBuilder 2.1 User's Manual. [cited 2018 Jun 3] Available from: http:// www.designbuildersoftware.com/docs/designbuilder/ DesignBuilder_2.1_Users-Manual_Ltr.pdf.

37. Altan H, Mohelnikova J, Hofman P. Thermal and Daylight Evaluation of Building Zones. Energy Procedia 2015; 78: 2784-9. doi: 10.1016/j.egypro.2015.11.626.

38. Yasar Y, Kalfa SM. The effects of window alternatives on energy efficiency and building economy in high-rise residential buildings in moderate to humid climates. Energy Convers Manag 2012; 64: 170-81. doi: 10.1016/j. enconman.2012.05.023.

39. Yu J, Yang C, Tian L. Low-energy envelope design of residential building in hot summer and cold winter zone in China. Energy Build 2008; 40(8): 1536-46. doi: 10.1016/j. enbuild.2008.02.020.

40. Eskin N, Turkmen H. Analysis of annual heating and cooling energy requirements for office buildings in different climates in Turkey. Energy Build 2008; 40(5): 763-73. doi: 10.1016/j.enbuild.2007.05.008.

41. Neto AH, Fiorelli FA. Comparison between detailed model simulation and artificial neural network for forecasting building energy consumption. Energy Build 2008; 40(12): 2169-76. doi: 10.1016/j.enbuild.2008.06.013.

42. Zomorodian ZS, Tahsildoost M. Validation of energy 
simulation programs: an empirical and comparative approach. Iran J Energy 2016; 18(4): 115-32. [In Persian].

43. IES Daylight Metrics Committee. IES Spatial Daylight Autonomy (SDA) and Annual Sunlight Exposure (ASE). New York: Illuminating Engineering Society; 2013.

44. CIBSE. Code for Interior Lighting. London, UK: Charteredn Institution of Building Services Engineers (CIBSE); 1994.

45. Dubois MC. Impact of Solar Shading Devices on Daylight
Quality: Measurements in Experimental Office Rooms. Lund, Sweden: Lund University; 2001.

46. International Commission on Illumination. No 29.2. Guide on Interior Lighting. Vienna: CIE; 1986.

47. Hanselaer P, Lootens C, Ryckaert W, Deconinck G, Rombauts P. Power density targets for efficient lighting of interior task areas. Light Res Technol 2007; 39(2): 171-84. doi: $\quad 10.1177 / 1365782807076737$. 